\section{A phonemic analysis of nine samples of glossolalic speech}

\author{
ERNEST BRYANT and DANIEL O'CONNELL \\ Saint Louis University, St. Louis, Mo. 63103
}

In nine tape-recorded samples of glossolalia, there is a remarkably low correlation with English samples from the same $S$ s, ascribable primarily to variation in vowel frequency. Nonetheless, all glossolalic phonemes are within the normal phonemic repertoire of native speakers of English. There is a divergence of syllables per pause rates between glossolalia and English. Optional articulatory choices characteristic of glossolalic samples can evidently be studied by means of accepted scientific procedures independently of theological or religious explication.

In the last decade a remarkable amount has been written and said about the topic of glossolalia in ancient and contemporary religion. This sudden upsurge in interest seems to be the result of the corresponding growth of Pentecostalism among world religions and the concurrent spread of speaking in tongues, a phenomenon said to be caused by the indwelling of the Spirit of God. Research into the various subcodes of glossolalia has been done by Wolfram (1966) and Nida (1964). They concluded that the phonemes used by glossolalia speakers were closely associated with the language background of the person. If foreign language systems were used, a much greater divergence of phoneme occurrence would be expected, but the opposite is the case. The phonemic code is more restricted than in the speaker's native language. Similar results were reported by Jaquith (1967) concerning the occurrence of English phonemes in glossolalic speech. He reported that all the phonemes used in his glossolalic sample had been observed in the casual speech of the speaker or would, at least, have been permissible there. For a review of the more recent literature, see Hine (1969) and Pattison (1968).

The purpose of the present study is an objective consideration of the phenomenon in itself, that is to say, a study of verbalized utterances. Our assumption has been scientific, not theological, and the conclusions drawn have been based entirely on the data and the analytic procedures. We have felt justified in prescinding in the present discussion from the ultimate question regarding the ordinary or extraordinary nature of the phenomenon as a religious experience or as a gift of remarkable origin, be it preternatural or supernatural. We feel that a scientific approach can make a significant contribution to understanding the phenomenon. We do not claim in any sense that such an approach is a substitute for a theological or religious one, nor do we mean to derogate from such approaches.

\section{PROCEDURES}

By glossolalia or speaking in tongues, we mean, in the present context, simply a verbalized utterance in a religious context which is intended and accepted as such by a Pentecostal community.

The Ss of our study were three speakers of glossolalia from very different backgrounds. Nine samples of glossolalia were gathered from these Ss under varying conditions. The first $S$ was a middle-aged Caucasian Southern Baptist business man who was delivering a sermon at a large religious convention ( $\mathrm{F}$ ull Gospel Business Men's Fellowship International). At one point during the sermon he stopped, praised God, and broke into glossolalia. After his glossolalic utterance, he interpreted what he had said, praised God again, and repeated this procedure one more time. The second $S$ was a young Roman Catholic woman at a Pentecostal prayer meeting, during which she broke into spoken glossolalia followed by a period of sung glossolalia. Afterwards, she spoke briefly in English on a topic unrelated to her tongues experience. The third S was an elderly Negro woman who was interviewed at her home on two different occasions. The interview was channeled by the authors so as to have her explain her religious beliefs. During each of the interviews, two periods of glossolalia were recorded.

Our recordings were made on a UHER Royal Tape Recorder at $3^{3 / 4}$ in./sec speed. We then transcribed both the English and the glossolalia into the Trager-Smith phonetic notation (Roberts, 1965). Due to the complete lack of competing background noise and conversation, the tape recordings were of excellent fidelity. The phonetic transcription was made by the first author in consultation with the second author. The approximate length for each of the passages, English and glossolalic, was $420 \mathrm{sec}$

The relative frequencies of each phoneme were computed for individual $S$ s and for the entire group from the transcriptions. These relative frequencies were then compared and correlated (rank-order correlation coefficient) with both Roberts's (1965) and Hultzén, Allen, \& Miron's (1964) tables of phonemic probabilities. The normative tables were then correlated with each other. (Prior to correlating our data, we had to adjust the two normative tables due to a slight difference in categorization of phonemes.) For a complete listing of the correlations, refer to Table 1 . It is important to note that the degrees of freedom for consonant phonemes are 24 , while the degrees of freedom for vowels are only 14 .

In order to compare speaking and pause rate, each section of our tape-recorded data was run through a Brüel \& Kjaer audio frequency spectrometer and lever recorder, from which a printout of acoustic energy through time was obtained. This printout was then measured and analyzed in terms of syllables per second, syllables per pause, and for the English passage, words per pause. A complete listing of these rates is given in Table 2.

\section{CONCLUSIONS}

From the analyses of both English and glossolalic passages, the following conclusions can be drawn: (1) All the phonemes used in the glossolalic samples are in the normal repertoire of phonemes characteristic of the language of the speaker. The relative frequencies of specific phonemes, however, differ significantly from their occurrence in English. (2) There is a greater difference between the relative frequency of vowels in English and glossolalia (rho $=.01$ ) than between the relative frequency of consonants in English and glossolalia (rho $=.55$ ) (3) The vowel and consonant phonemes contributing most significantly to the low correlations are the following: ah, iy, ey, ow, $\partial, \mathrm{i}$, $g, \vartheta, \gtrsim$. (4) The occurrence of the phonemes $/ \partial /$ and $/ \partial /$ is significantly lower in glossolalia than in English. This is probably artifactual due to the absence of the articles "a" and "the" in glossolalia. (5) There is a significant correlation between each of the two sets of norms used and the English consonant sample, but a much lower correlation between the vowels and the Roberts norms. It is important to note, however, that Roberts's and Hultzén's norms for vowels only correlate .54 with each other. 'The reason for such a low correlation is unknown, but it does correspond to the very low Roberts-English correlation. 
Table 1

Rank-Order Correlation Coefficients of Phonemic Relative Frequencies in Glossolalia and English

\begin{tabular}{|c|c|c|c|c|c|c|}
\hline & \multicolumn{2}{|c|}{ English Sample } & \multicolumn{2}{|c|}{ Hultzén Norms } & \multicolumn{2}{|c|}{ Glossolalia } \\
\hline & Consonants & Vowels & Consonants & Vowels & Consonants & Vowels \\
\hline Roberts Norms & $.77 * *$ & .35 & $.98 * *$ & $.54 *$ & $.62 * *$ & .23 \\
\hline English Sample & - & - & $.72 * *$ & $.83^{* *}$ & $.55 * *$ & .01 \\
\hline Hultzén Norms & & & $-\cdots$ & - & $.61^{* *}$ & .15 \\
\hline
\end{tabular}

$* p<.05 ; * * p<.01$

Table 2

Speech Rates for English and Glossolalic Samples in Syllables Per Second, Syllables Per Pause, and For English Passages, Words Per Pause

\begin{tabular}{lccc} 
& Syllables/Second & Syllables/Pause & Words/Pause \\
\hline English & 3.0 & 10 & 7 \\
Glossolalic & 3.6 & 18 & - \\
\hline
\end{tabular}

Table 3

Consonant and Vowel Phonemes Contributing Most to Variability With Respective Relative Frequencies for English and Glossolalic Samples

\begin{tabular}{|c|c|c|c|c|c|}
\hline & \multicolumn{2}{|c|}{ Consonant Phonemes } & & \multicolumn{2}{|c|}{ Vowel Phonemes } \\
\hline & English (\%) & Glossolalia (\%) & & English (\%) & Glossolalia $\left(\mathscr{O}_{o}^{\circ}\right)$ \\
\hline \multirow{6}{*}{$\begin{array}{l}a \\
\partial \\
\partial\end{array}$} & 2.0 & 16.0 & ah & 1.7 & 23.6 \\
\hline & 0.5 & 7.0 & iy & 7.7 & 17.6 \\
\hline & 6.0 & 0.1 & ey & 3.3 & 10.1 \\
\hline & & & ow & 6.3 & 8.8 \\
\hline & & & $\partial$ & 24.0 & 6.0 \\
\hline & & & i & 14.9 & 2.0 \\
\hline
\end{tabular}

(6) English and glossolalia speech rates are very similar to the normative rate of spontaneous speech (O'Connell, Kowal, \& Hörmann, 1969), that is, 3.0 and 3.6 syllables/sec, respectively, as compared to normative data of 3.6 syllables/sec. (7) Our own observations lead us to conclude that it is not necessary to investigate glossolalic speech uniquely through theological or religious means. A scientific procedure is quite feasible. The phonemic frequencies found in the present study are not forced, and no phonemes foreign to the speaker which would cause violence to neuromuscular habits are employed.

\section{DISCUSSION}

As mentioned above, all the phonemes used by our Ss were within the normal repertoire of their spoken English. In fact, only one of the 38 possible phonemes was not used at all, namely, $/ \mathrm{J} /$. As Gerlach \& Hine (1968) have stated: "Pentecostal glossolalia frequently includes ... xenoglossie, speaking in a tongue foreign and unknown to the speaker. But the ecstatic utterances which members of our research team have heard during these three years of our study have only rarely involved such a foreign language, and in these cases it is probable that the speaker had previous acquaintance with at least some of the words of this language. Rather, these utterances have taken the form of sounds ranging from mutterings to meaningless, but speechlike syllables."
Our present research confirms this position. Of the 37 phonemes used in the glossolalic utterances, 6 phonemes tended to dominate: ah, iy, ey, ow, g, D. Table 3 gives each of these phonemes and their actual relative frequencies. Of these six phonemes, the phoneme /ah/ was by far the most frequently uttered. This fact was also noted by Wolfram (1966), Nida (1964), and Jaquith (1967). According to Jaquith, $53 \%$ of his glossolalic utterances consisted of vowel phonemes. The phoneme /ah/ was predominant with a relative frequency of $29.3 \%$ in one sample and $25.8 \%$ in another sample. One consideration in this regard is that the phoneme /ah/ is uttered when the articulatory musculature is in a relatively relaxed state. It requires little effort and can be repeated rapidly. This permits the speaker to be at ease and in a very relaxed state during his period of to the most common utterance of infants. It is also noteworthy that four of the six phonemes which are variant are vowels. This further enhances the relaxed characteristic since vowels are produced in a relatively continuous manner and do not require the neuromuscular precision required by consonants.

It is important to note that, although our glossolalic data on vowel frequencies are similar to those reported by Jaquith, there is, nevertheless, considerable divergence tongues. It also happens to be similar between his study and ours as to the distribution patterns of these phonemes in English and glossolalia. Jaquith has stated that the distribution patterns of phonemes in his glossolalic samples are the same as the pattern: of his English samples. He offers no evidence in support of this position. Rather, his own data clearly show that this position is highly improbable. He has stated that the phoneme /ah/ had relative frequencies of $29.3 \%$ and $25.8 \%$ in his glossolalic samples. But Hultzén, Allen, \& Miron's (1964) normative tables for English list the relative frequency of the phoneme /ah/ as only $0.5 \%$, while Roberts's (1965) normative tables give a relative frequency of only $3.3 \%$. Jaquith further reports a $0.0 \%$ and $1.9 \%$ relative frequency for the phoneme /ə/, compared to Hultzén, Allen, and Miron's listing of $22.6 \%$ and Roberts's listing of $32.7 \%$ for English. The data of the present paper are consonant with the normative tables. Our English samples yielded a $1.7 \%$ relative frequency for the phoneme /ah/ and a $24.0 \%$ relative frequency for the phoneme /a/. A rank-order correlation between the English and glossolalic samples yielded an extremely low correlation (rho $=.01$ ).

The next phase of our study concerned pause and speech rates of English and glossolalia. A pause time minimum was set at $250 \mathrm{msec}$, according to Goldman-Eisler's (1968) convention. As seen in Table 2 , the syllables/second rates of both sequences were very similar. This would seem to indicate that both were very near the rate used in normal spontaneous speech. However, the scores obtained for the syllables/pause scale reflect considerable divergence between the two sequences. Though the duration times in syllables/second were nearly the same for both passages, the distribution of syllables and phonemes per phrase was considerably different in English from that of glossolalia; that is, in the English sample there were, on the average, only 10 syllables between pauses, while in the glossolalic sample there were, on the average, 18 syllables between pauses. Since pause rate is crucial for spontaneous communicative speech, it would indicate that the spontaneous communicative character of speech is somehow altered and perhaps diminished in glossolalia.

In summary, then, there is a remarkably low correlation between the glossolalic and English samples, ascribable primarily to variation in vowel frequency. Nonetheless, all glossolalic phonemes are within the normal phonemic repertoire of native speakers of English. There is a 
divergence of syllable/pause rates between glossolalia and English. We conclude, therefore, that optional articulatory choices characteristic of the glossolalic samples can legitimately be studied by means of accepted scientific procedures and do not necessarily require theological or religious explication.

\section{REFERENCES}

GERLACH, L.. \& HINE, V. Fire factors crucial to the growth and spread of a modern religious movement. Journal for the Scientific Study of Religion, 1968, ?, 23-40.

GOLDMAN-EISLER, F. Psycholinguistics: Experiments in spontaneous speech London: Academic Press, 1968

GOODMIAN, F. Phonetic analysis of glossolalia in four cultural settings. Journal for the Scientific Study of Religion, 1969, 8, 227-239.

HINE, V. Pentecostal glossolalia: Toward a functional interpretation. Journal for the
Scientific Study of Religion, 1969. 8. 211-226

HULTZEN, L., ALLEN. J.. \& MIRON. M Tables of transitional frequencies of English phonemes. Urbana, Ill: University of Illinois Press, 1964.

JAQUITH, J. Toward a ty pology of formal communicative behaviors: Glossolalia. Anthropological Linguistics, 1967, 9, 1-8.

NIDA, E. Preliminary report on glossolalia. Paper presented at the meeting of the Linguistic Society of America, New York, December 1964

O'CONNELL, D., KOWAL, S., \& HURMANN, H. Semantic determinants of pauses. Psychologische Forschung. 1969, 33, 50-67.

PATTISON, E. Behavioral science research on the nature of glossolalia. Journal of the American Scientific Affiliation, 1968 , $20,73-86$.

ROBERTS, A. A statistical linguistic analysis of American English. The Hague: Iouton, 1965.

WOLFRAM, W. The sociolinguistics of glossolalia. Unpublished Master's thesis. Hartford Seminary Foundation, 1966.

\title{
Attraction and relevancy of attitude similarity-dissimilarity: Impersonal topics and friendship beliefs
}

\author{
JOHN J. LA GAIPA and RON E. WERNER \\ University of Windsor, Windsor, Ontario, Canada
}

Three levels of attitude similarity were created in an intrastranger design. Within high and low levels of agreement, the more relevant friendship topics and the less relevant impersonal topics were assigned equal weights. Within an intermediate level of agreement, the two topics were assigned differential weights. Agreement on friendship did not evoke more attraction toward the stranger than agreement on impersonal topics. The level of agreement rather than topic relevancy affected liking and the expected level of friendship.

A proposition on the relevancy of similarity is found in several theories of interpersonal attraction. Newcomb (1956) postulates that the relationship between perceived similarity and attraction varies as a function of the importance and common relevance of the object of the attitude. Research on topic importance has produced findings that are equivocal (Byrne, 1961), negative (Byrne \& Nelson, 1964, 1965), and positive (Byrne, London, \& Griffith, 1968; Clore \& Baldridge, 1968). These studies have been concerned with attitudes toward impersonal issues rather than with issues more directly related to affiliation.

The process of friendship formation involves an active search for increasingly meaningful areas of similarity (Fiebert \& Fiebert, 1969). It was proposed in the present study that agreement on friendship expectations and beliefs regarding the nature of friendship may be more relevant to friendship formation than agreement on social and political issues. Relevancy was defined in terms of the instrumental value of the topic to the receiver for a specific purpose or goal. It was hypothesized that a higher level of attraction would be evoked toward a stranger who expressed agreement on friendship expectations and disagreement on impersonal topics than toward a stranger who expressed agreement on impersonal topics and disagreement on friendship topics.

The failure of several studies to demonstrate the influence of topic importance on attraction has been explained in terms of experimental designs in which agreement and disagreement occurred on topics that were equally important or unimportant (Byrne, London, \& Griffith, 1968; Clore \& Baldridge, 1968). These investigators found support for topic effects by differentially weighting topic importance or interest within each level of agreement-disagreement. In the present study, topics heterogeneous in relevancy were associated with one stranger.

\section{METHOD}

A total of 99 students in introductory courses in psychology at the University of Windsor rated the items from two questionnaires for relevancy and/or importance. A different group of 80 Ss made judgments about an anonymous stranger on the basis of his responses on these questionnaires. A shortened version of the Friendship Expectancy (FE) Scale was used. The 20 items represented the subscales dealing with acceptance, admiration, openness, and ritualistic social exchange. The Social Attitudes (SA) Scale contains 28 items on such impersonal topics as student power, authority, drugs, and sex. Each of the items in a modified version of the FE scale was rated by 47 Ss for its relevancy for friendship with a social acquaintance on a 9-point scale of relevancy. The items in a modified version of the SA scale were similarly rated by 52 Ss on a relevancy scale for friendship. In a later session, the same 52 Ss rated each of the SA scale items for topic importance on a 9 -point scale of importance.

The perceived relevancy of the friendship items $(M=6.78, S D=1.04)$ was greater than the perceived relevancy of the impersonal items $(M=4.24, S D=1.29)$. The difference between means was significant $(t=10.72, d f=1 / 97, p<.001)$. The FE scale was accordingly designated as measuring a topic of high relevancy, and the SA scale was designated as measuring a topic of low relevancy to friendship. The means and standard deviation of the ratings of the SA items on topic importance was also determined $(\mathrm{M}=5.83, \mathrm{SD}=.67)$. In addition, a product-moment correlation was computed between each S's total scores based on the ratings of the $\mathrm{SA}$ items on importance and relevancy $(\mathrm{r}=.42, \mathrm{df}=50$, $p<.01$ ).

Two questionnaires were initially administered to several classes to obtain measures of the attitudes of the students. The order of presentation of the scales was varied. In completing the IE scale, the $S$ s were instructed to 